\title{
Microwave spectrum, dipole moment, structure, and internal rotation of the cyclopropane-sulfur dioxide van der Waals complex
}

\author{
Anne M. Andrews, Kurt W. Hillig II, and Robert L. Kuczkowski \\ Department of Chemistry, University of Michigan, Ann Arbor, Michigan 48109-1055
}

(Received 29 July 1991; accepted 23 October 1991)

\begin{abstract}
The rotational spectrum of the cyclopropane-sulfur dioxide complex was observed by Fourier transform microwave spectroscopy. The spectrum exhibited $a$ - and $c$-dipole selection rules with the $c$-dipole transitions split into doublets of unequal intensity separated by about 150 $\mathrm{kHz}$. The structure has $C_{s}$ symmetry with the sulfur and carbon atoms all lying in the $a c$ plane; the oxygen and hydrogen atoms straddle the plane. The sulfur dioxide plane is nearly parallel to a $\mathrm{C}-\mathrm{C}$ bond edge. The distance from the center of mass of the $\mathrm{SO}_{2}$ to the $\mathrm{C}-\mathrm{C}$ bond center is $3.295 \AA$. The dipole moment of the complex is 1.681 (1) D, with components $\mu_{a}=0.815$ (1) D and $\mu_{c}=1.470(1) \mathrm{D}$. The splittings in the spectrum arise from an internal rotation of the cyclopropane subunit about its local $C_{2}$ axis which lies nearly along the line connecting the centers of mass.
\end{abstract}

\section{INTRODUCTION}

Complexes of $\mathrm{HF}, \mathrm{HCl}$, and $\mathrm{HCN}$ with the hydrocarbon series ethylene, ${ }^{1-3}$ acetylene, ${ }^{4-6}$ and cyclopropane ${ }^{7-9}$ have been studied recently. In each complex, the acid is hydrogen bonded to the $\pi$ (ethylene and acetylene) or pseudo$\pi$ (cyclopropane) system. ${ }^{10}$ It has been noted that for each HX series there is a decrease in hydrogen-bond length, an increase in pseudodiatomic stretching force constant, and an increase in induced dipole moment from ethylene to acetylene to cyclopropane. ${ }^{11,12}$ As these properties are often correlated with the strength of the interaction, this has led to a discussion that the pseudo- $\pi$ system of cyclopropane forms stronger hydrogen bonds than the classical $\pi$ systems of ethylene and acetylene. Legon and Millen, studying the pseudodiatomic force constants of the $\mathrm{HCl}$ and $\mathrm{HCN}$ series, have assigned nucleophilicities to $\mathrm{C}_{2} \mathrm{H}_{4}$ (4.7), $\mathrm{C}_{2} \mathrm{H}_{2}$ (5.1), and $\mathrm{C}_{3} \mathrm{H}_{6}$ (6.4). ${ }^{12}$

While these trends are well documented for the hydrocarbon-acid complexes, which are hydrogen bonded, there is less data for this hydrocarbon series complexed to a nonhydrogen-bonding partner. Recently in our lab the complexes of ethylene and acetylene with sulfur dioxide have been observed. ${ }^{13,14}$ In both cases, the complexes have a stacked structure with the $C_{2}$ axis of the $\mathrm{SO}_{2}$ crossed at $90^{\circ}$ to the $\mathrm{C}=\mathrm{C}$ or $\mathrm{C} \equiv \mathrm{C}$ bond. The sulfur of the $\mathrm{SO}_{2}$ apparently interacts with the $\pi$ system of the ethylene and acetylene. Like the acid complexes, it was observed that the interaction distance, as measured from the $\mathrm{C}-\mathrm{C}$ bond center to the sulfur, is shorter for $\mathrm{C}_{2} \mathrm{H}_{2} \cdot \mathrm{SO}_{2}(3.359 \AA)$ than $\mathrm{C}_{2} \mathrm{H}_{4} \cdot \mathrm{SO}_{2}$ (3.446 $\AA$ ) and that the induced dipole moment is greater for $\mathrm{C}_{2} \mathrm{H}_{2} \cdot \mathrm{SO}_{2}$. The force constants for the stretching vibration between the hydrocarbon and the $\mathrm{SO}_{2}$ are not easily compared due to the effect of internal rotation in $\mathrm{C}_{2} \mathrm{H}_{4} \cdot \mathrm{SO}_{2}$. This is discussed in Ref. 14.

Here we report on the cyclopropane $\cdot \mathrm{SO}_{2}\left(\mathrm{C}_{3} \mathrm{H}_{6} \cdot \mathrm{SO}_{2}\right)$ complex. The sulfur atom interacts with the pseudo- $\pi$ system as expected, however, the structure is slightly different from the $\mathrm{C}_{2} \mathrm{H}_{4} \cdot \mathrm{SO}_{2}$ and $\mathrm{C}_{2} \mathrm{H}_{2} \cdot \mathrm{SO}_{2}$ complexes in that the $C_{2}$ axis of the $\mathrm{SO}_{2}$ is nearly parallel to the $\mathrm{C}-\mathrm{C}$ bond, rather than crossed at $90^{\circ}$. The interaction distance ( $\mathrm{S}$ to $\mathrm{C}-\mathrm{C}$ bond center) of $3.203 \AA$ is shorter than in $\mathrm{C}_{2} \mathrm{H}_{2} \cdot \mathrm{SO}_{2}$. Moreover, the induced dipole moment and the pseudodiatomic force constant are both greater.

\section{EXPERIMENT}

\section{A. Spectrometer}

The spectrum was observed in a Fourier transform microwave spectrometer of the Balle-Flygare type which has been described previously. ${ }^{15,16}$ The molecular beam was generated with a modified Bosch fuel injector. Linewidths were typically $20-30 \mathrm{kHz}$ full width at half maximum (FWHM) and center frequencies were estimated to be accurate to $\pm 2-3 \mathrm{kHz}$. For deuterated isotopomers, transitions were broadened to $100 \mathrm{kHz}$ or more from unresolved nuclear quadrupole hyperfine structure and line centers were accurate to $\pm 20-30 \mathrm{kHz}$. Stark effects were measured by applying up to $10000 \mathrm{~V}$ with opposite polarities to two parallel steel mesh plates separated by about $30 \mathrm{~cm}$.

\section{B. Samples}

The spectrum of $\mathrm{C}_{3} \mathrm{H}_{6} \cdot \mathrm{SO}_{2}$ was observed with a mixture of approximately $1 \%$ each of $\mathrm{C}_{3} \mathrm{H}_{6}$ (Aldrich) and $\mathrm{SO}_{2}$ (Matheson) in Ar at a total pressure of $1.5 \mathrm{~atm} . \mathrm{S}^{18} \mathrm{O}_{2}(98 \%$ ${ }^{18} \mathrm{O}$ ) was purchased from Alfa Products and used without dilution to observe the $\mathrm{C}_{3} \mathrm{H}_{6} \cdot \mathrm{S}^{18} \mathrm{O}_{2}$ spectrum. A 50:50 mixture of $\mathrm{S}^{18} \mathrm{O}_{2}$ and $\mathrm{S}^{16} \mathrm{O}_{2}$ was used to produce the $\mathrm{C}_{3} \mathrm{H}_{6} \cdot \mathrm{S}^{18} \mathrm{O}^{16} \mathrm{O}$ spectrum; the samples exchanged immediately upon mixing. The $\mathrm{C}_{3} \mathrm{H}_{6} \cdot{ }^{34} \mathrm{SO}_{2}$ spectrum was observed in natural abundance $\left(4 \%{ }^{34} \mathrm{~S}\right), \mathrm{C}_{3} \mathrm{D}_{6}(98 \% \mathrm{D})$ and $1,1-C_{3} H_{4} D_{2}$ (98\%) were purchased from MSD isotopes.

$\mathrm{C}_{3} \mathrm{H}_{5} \mathrm{D}$ was synthesized in poor yield as follows. Cyclopropyl Grignard reagent was produced by reacting cyclopropyl bromide (Aldrich) with $\mathrm{Mg}$ (Baker) in dry diethyl ether in the usual manner. The flask containing the Grignard reagent was then placed in line with a trap cooled with a $\mathrm{CCl}_{4}$ slush $\left(-25^{\circ} \mathrm{C}\right)$ followed by a liquid-nitrogen trap $\left(-196^{\circ} \mathrm{C}\right)$ which was isolated from the atmosphere by a mercury bubbler. Nitrogen gas was passed through the apparatus while $\mathrm{D}_{2} \mathrm{O}$ (Cambridge Isotope Lab) was slowly 
TABLE I. Observed transitions in $\mathrm{MHz}$ of $\mathrm{C}_{3} \mathrm{H}_{6} \cdot \mathrm{SO}_{2}$.

\begin{tabular}{|c|c|c|c|c|c|}
\hline$J_{K, N_{0}}^{\prime}$ & $J_{X, K_{0}}^{\prime \prime}$ & $A_{1} / A_{2}{ }^{a}$ & $J_{K_{p} K_{0}}^{\prime}$ & $J_{K_{P} K_{0}}^{\prime \prime}$ & $A_{1} / A_{2}$ \\
\hline $3_{03}$ & 202 & 7311.753 & $5_{23}$ & $4_{22}$ & 12207.788 \\
\hline $3_{22}$ & 221 & 7315.089 & $5_{14}$ & $4_{13}$ & 12383.484 \\
\hline $3_{21}$ & 220 & 7318.850 & $6_{16}$ & $5_{15}$ & 14387.127 \\
\hline 3,12 & 211 & 7432.386 & $6_{06}$ & $5_{05}$ & 14597.283 \\
\hline $4_{14}$ & $3_{13}$ & 9595.002 & $6_{15}$ & $S_{14}$ & 14856.965 \\
\hline 404 & $3_{03}$ & 9744.449 & $7_{17}$ & $6_{16}$ & 16780.978 \\
\hline 423 & $3_{22}$ & 9752.487 & $7_{07}$ & $6_{00}$ & 17015.605 \\
\hline $4_{32}$ & $3_{31}$ & 9754.511 & $77_{16}$ & $6_{15}$ & 17382.667 \\
\hline $4_{31}$ & $3_{30}$ & 9754.584 & $22_{21}$ & $2_{11}$ & 14754.456 \\
\hline $4_{22}$ & $3_{21}$ & 9761.865 & 220 & 212 & 14990.582 \\
\hline $4_{13}$ & $3_{12}$ & 9908.517 & $3_{21}$ & $3_{13}$ & 15112.216 \\
\hline $5_{15}$ & $4_{14}$ & 11991.722 & $4_{22}$ & $4_{14}$ & 15279.080 \\
\hline$s_{0 s}$ & $4_{04}$ & 12173.271 & $5_{23}$ & $5_{15}$ & 15495.147 \\
\hline \multirow[t]{2}{*}{$5_{24}$} & $4_{23}$ & 12189.058 & & & \\
\hline & & $A_{2}$ (strong) & & \multicolumn{2}{|l|}{$A_{1}$ (weak) } \\
\hline $1_{10}$ & $0_{\infty}$ & 7435.084 & & \multicolumn{2}{|l|}{7435.245} \\
\hline 211 & $1_{01}$ & 9951.926 & & \multicolumn{2}{|l|}{9952.070} \\
\hline $3_{12}$ & 202 & 12508.184 & & \multicolumn{2}{|l|}{12508.346} \\
\hline $4_{13}$ & $3_{03}$ & 15104.949 & & \multicolumn{2}{|l|}{15105.104} \\
\hline $6_{006}$ & $5_{14}$ & 9026.565 & & \multicolumn{2}{|l|}{9026.412} \\
\hline 707 & $6_{15}$ & 11185.201 & & \multicolumn{2}{|l|}{11185.039} \\
\hline
\end{tabular}

- Symmetry designation of tunneling doublets. $A_{1} / A_{2}$ indicales that the transition was unsplit.

added dropwise to the cyclopropyl Grignard. Excess $\mathrm{D}_{2} \mathrm{O}$ and ether were trapped in the $\mathrm{CCl}_{4}$ trap and a small amount of $\mathrm{C}_{3} \mathrm{H}_{5} \mathrm{D}$ was collected in the liquid-nitrogen trap.

\section{RESULTS AND ANALYSIS}

\section{A. Spectrum}

The spectrum of $\mathrm{C}_{3} \mathrm{H}_{6} \cdot \mathrm{SO}_{2}$ exhibited $a$ - and $c$-dipole selection rules. The $c$-type $R$-branch transitions were split into doublets of unequal intensity and the strong and weak $c$ type transitions were each fit independently with the $a$-type transitions to a Watson $S$-reduced Hamiltonian. ${ }^{17}$ The observed transitions are listed in Table I and the derived constants are shown in Table II. The splitting of the $c$-type transitions arises from an internal rotation of the cyclopropane subunit exchanging three pairs of protons (see internal rotation section below ) and the $A_{1}$ and $A_{2}$ symmetry labels of the states are taken by analogy to ethylene $\cdot \mathrm{SO}_{2}$ which has a similar tunneling path. ${ }^{13}$ For $\mathrm{C}_{3} \mathrm{H}_{6} \cdot \mathrm{SO}_{2}$, the $A_{1}$ label corresponds to the weaker transitions and the $A_{2}$ to the stronger. Additional effects of the internal rotation are seen in the difference in the sign of the $D_{K}$ distortion constant between the $A_{1}$ and $A_{2}$ states. A similar effect was observed in the ethylene $\cdot \mathrm{SO}_{2}$ complex and it is believed to arise from neglect of an internal rotation term in the Hamiltonian.

The spectra of $\mathrm{C}_{3} \mathrm{H}_{6} \cdot{ }^{34} \mathrm{SO}_{2}, \mathrm{C}_{3} \mathrm{H}_{6} \cdot \mathrm{S}^{18} \mathrm{O}_{2}$, and $\mathrm{C}_{3} \mathrm{H}_{6} \cdot \mathrm{S}^{18} \mathrm{O}^{16} \mathrm{O}$ were also all split into doublets, with the same relative intensity pattern as the normal isotopic species. For $\mathrm{C}_{3} \mathrm{H}_{6} \cdot \mathrm{S}^{18} \mathrm{O}_{2}$ and $\mathrm{C}_{3} \mathrm{H}_{6} \cdot \mathrm{S}^{18} \mathrm{O}^{16} \mathrm{O}$, the magnitude of the splitting of the $2_{11}-1_{01}$ transitions decreased by $30 \%$ and $10 \%$, respectively. For $\mathrm{C}_{3} \mathrm{H}_{6} \cdot{ }^{34} \mathrm{SO}_{2}$, the splitting increased by $10 \%$. In the $\mathrm{C}_{3} \mathrm{D}_{6} \cdot \mathrm{SO}_{2}$, the doublets were unresolved due to deuterium nuclear quadrupole broadening. For $\mathrm{C}_{3} \mathrm{H}_{5} \mathrm{D} \cdot \mathrm{SO}_{2}$ the transitions were unsplit. Two different spectra were observed for the $1,1-\mathrm{C}_{3} \mathrm{H}_{4} \mathrm{D}_{2} \cdot \mathrm{SO}_{2}$ isotopic species; one was split into doublets (labeled apical) and the other was unsplit (labeled basal). These labels will be dis-

TABLE II. Spectroscopic constants (Watson $S$ reduction; $I^{r}$ representation) of $\mathrm{C}_{3} \mathrm{H}_{6} \cdot \mathrm{SO}_{2}$.

\begin{tabular}{|c|c|c|}
\hline & $A_{2}{ }^{\mathrm{a}}$ & $A_{1}$ \\
\hline$A / \mathrm{MHz}$ & $6176.635(5)^{b}$ & $6176.828(5)$ \\
\hline$B / \mathrm{MHz}$ & $1258.500(1)$ & $1258.500(1)$ \\
\hline$C / \mathrm{MHz}$ & $1180.101(1)$ & $1180.101(1)$ \\
\hline$D_{J} / \mathrm{kHz}$ & $1.958(5)$ & $1.959(6)$ \\
\hline$D_{J K} / \mathrm{kHz}$ & $15.5(1)$ & $15.4(2)$ \\
\hline$D_{K} / \mathrm{kHz}$ & $-18.1(9)$ & $20.5(11)$ \\
\hline$d_{1} / \mathrm{kHz}$ & $-0.078(4)$ & $-0.077(5)$ \\
\hline$d_{2} / \mathrm{kHz}$ & $0.179(6)$ & $0.178(7)$ \\
\hline$H_{K J} / \mathrm{kHz}$ & $0.9(1)$ & $0.8(2)$ \\
\hline$h_{3} / \mathrm{kHz}$ & $0.04(1)$ & $0.04(1)$ \\
\hline$n^{\mathrm{c}}$ & 33 & 33 \\
\hline$\Delta v_{\mathrm{rms}} \mathrm{d} / \mathrm{kHz}$ & 6 & 7 \\
\hline$\mu_{a} / \mathrm{D}$ & $0.815(1)$ & \\
\hline$\mu_{c} / \mathrm{D}$ & $1.470(1)$ & \\
\hline$\mu_{T} / \mathrm{D}$ & $1.681(1)$ & \\
\hline
\end{tabular}

a Symmetry label of tunneling state (see text).

${ }^{b}$ Uncertainties represent $1 \sigma$ in the least-squares fit.

${ }^{c}$ Number of transitions in the fit.

${ }^{\mathrm{d}} \Delta v=v_{\mathrm{obs}}-v_{\text {calc }}$. 


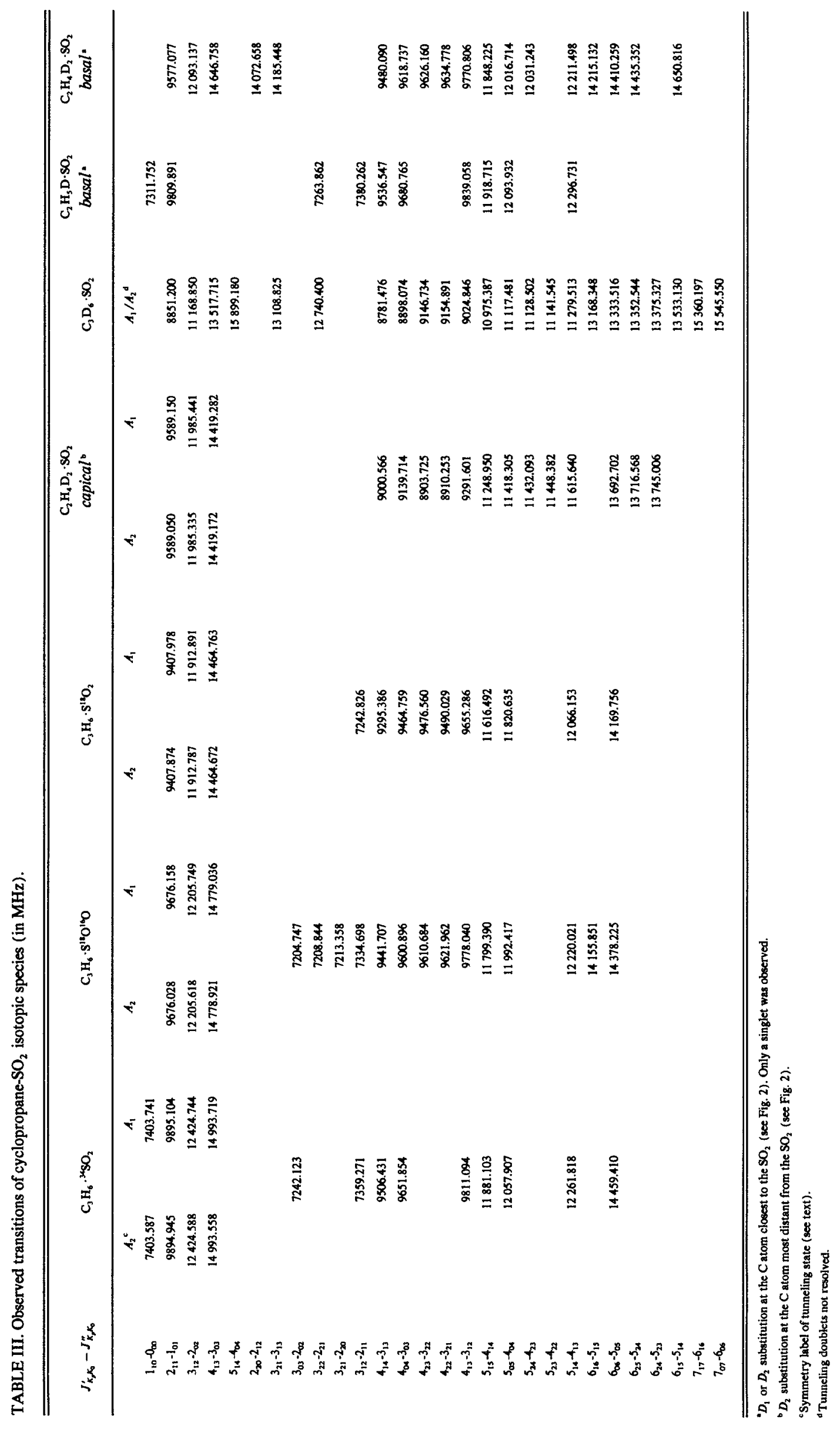


TABLE IV. Spectroscopic constants for $\mathrm{C}_{3} \mathrm{H}_{0} \cdot \mathrm{SO}_{2}$ isotopic species.

\begin{tabular}{|c|c|c|c|c|c|c|}
\hline & Symmetry & $A / \mathrm{MHz}$ & $B / \mathrm{MHz}$ & $C / \mathrm{MHz}$ & $n^{\mathrm{b}}$ & $\Delta v_{\mathrm{rms}}{ }^{\mathrm{c}}$ \\
\hline \multirow[t]{2}{*}{$\mathrm{C}_{3} \mathrm{H}_{6} \cdot \mathrm{SO}_{2}$} & $A_{1}$ & $6176.635(5)^{d}$ & $1258.500(1)$ & $1180.101(1)$ & 33 & 6 \\
\hline & $A_{2}$ & $6176.828(5)$ & $1258.500(1)$ & $1180.101(1)$ & 33 & 7 \\
\hline \multirow[t]{2}{*}{$\mathrm{C}_{3} \mathrm{H}_{6} \cdot{ }^{34} \mathrm{SO}_{2}$} & $A_{1}$ & $6157.911(7)$ & $1245.746(2)$ & $1169.572(2)$ & 13 & 9 \\
\hline & $A_{2}$ & $6158.066(7)$ & $1245.745(2)$ & $1169.571(2)$ & 13 & 10 \\
\hline \multirow{2}{*}{$\mathrm{C}_{3} \mathrm{H}_{6} \cdot \mathrm{S}^{18} \mathrm{O}_{2}$} & $A_{1}$ & $5718.558(2)$ & $1229.851(1)$ & $1139.843(1)$ & 13 & 11 \\
\hline & $A_{2}$ & $5718.664(4)$ & $1229.850(1)$ & $1139.845(1)$ & 13 & 3 \\
\hline \multirow[t]{2}{*}{$\mathrm{C}_{3} \mathrm{H}_{6} \cdot \mathrm{S}^{18} \mathrm{O}^{16} \mathrm{O}$} & $A_{1}$ & $5945.214(3)$ & $1243.685(1)$ & $1159.500(1)$ & 17 & 3 \\
\hline & $A_{2}$ & $5945.345(3)$ & $1243.684(1)$ & $1159.501(1)$ & 17 & 2 \\
\hline \multirow[t]{2}{*}{$\begin{array}{l}1,1-\mathrm{C}_{3} \mathrm{H}_{4} \mathrm{D}_{2} \cdot \mathrm{SO}_{2} \\
(\text { apical })^{\mathrm{f}}\end{array}$} & $A_{1}$ & $6049.426(5)$ & $1179.925(1)$ & $1107.162(1)$ & 16 & 6 \\
\hline & $A_{2}$ & $6049.523(5)$ & $1179.926(1)$ & $1107.162(1)$ & 15 & 5 \\
\hline $\mathrm{C}_{3} \mathrm{D}_{0} \cdot \mathrm{SO}_{2}$ & $A_{1} / A_{2}{ }^{\circ}$ & $5420.840(57)$ & $1143.558(1)$ & $1082.701(1)$ & 30 & 6 \\
\hline \multirow{2}{*}{$\begin{array}{l}\mathrm{C}_{3} \mathrm{H}_{3} \mathrm{D} \cdot \mathrm{SO}_{2} \\
(\text { basal })^{2} \\
1,1-\mathrm{C}_{3} \mathrm{H}_{4} \mathrm{D}_{2} \cdot \mathrm{SO}_{2} \\
(\text { basal })^{\mathrm{f}_{8}}\end{array}$} & & $6062.694(14)$ & $1249.091(3)$ & $1173.458(4)$ & 10 & 18 \\
\hline & & $5857.749(6)$ & $1239.833(1)$ & $1167.135(1)$ & 19 & 4 \\
\hline
\end{tabular}

-Symmetry label of tunneling state (see text).

${ }^{\circ}$ Number of transitions in fit.

${ }^{\circ} \Delta v=v_{\text {obs }}-v_{\text {calc }}$.

dUncertainty is $1 \sigma$.

'Tunneling doublets not resolved for $\mathrm{C}_{3} \mathrm{D}_{6} \cdot \mathrm{SO}_{2}$.

${ }^{\prime}$ See footnote to Table III for explanation of apical and basal labels for 1,1- $\mathrm{C}_{3} \mathrm{H}_{4} \mathrm{D}_{2} \cdot \mathrm{SO}_{2}$.

No tunneling doublets observed for these isotopomers.

cussed in Sec. III C. For the spectrum of the apical species both tunneling doublets were very weak, making it difficult to assign strong and weak components. Therefore, the symmetry labels were assigned by higher/lower frequency to be consistent with the other isotopic species. The magnitude of the splitting decreased by $30 \%$. The transitions for the isotopomers are listed in Table III and the rotational constants are given in Table IV; because the fitted distortion constants were similar to those for the normal isotopic form, only $A, B$, and $C$ are reported for the isotopomers.

\section{B. Dipole moments}

The dipole moment of the complex was measured by tracking the Stark effect of seven $M$ components from four transitions with increasing electric field. The electric field was calibrated using the $J=1 \leftarrow 0, M=0 \leftarrow 0$ transition of OCS at $12162.980 \mathrm{MHz} .^{18}$ The observed Stark effects were least-squares fit to dipole components $\mu_{a}=0.815$ (1) D and $\mu_{c}=1.470$ (1) D resulting in $\mu_{T}=1.681$ (1) D. When $\mu_{b}$ was included in the fit, the value for $\mu_{b}^{2}$ was $0.030(50) \mathrm{D}$, indicating that $\mu_{b}$ was zero. The dipole moment components of basal- $\mathrm{C}_{3} \mathrm{H}_{4} \mathrm{D}_{2} \cdot \mathrm{SO}_{2}$ were also determined as $\mu_{a}=0.803(3) \mathrm{D}$ and $\mu_{c}=1.482(3) \mathrm{D}$ from six $M$ components from two transitions.

\section{Structure}

It was assumed in the structural analysis that the geometries of the cyclopropane and sulfur dioxide were not changed upon complexation from their free gas-phase structures. ${ }^{19,20}$ The moments of inertia and planar second moments of the stronger set of transitions were used for the isotopic species which exhibited splittings. Because the difference in rotational constants is very small $(<200 \mathrm{kHz})$, this choice will not markedly affect the determination of the structure. The planar moments for $\mathrm{C}_{3} \mathrm{H}_{6} \cdot \mathrm{SO}_{2}$, $\mathrm{C}_{3} \mathrm{H}_{6} \cdot{ }^{34} \mathrm{SO}_{2}$, cyclopropane, and sulfur dioxide are listed in Table V.

The $a$ - and $c$-type selection rules and the absence of evidence for a $\mu_{b}$ dipole component suggest that the complex has an $a c$ symmetry plane. Comparison of the planar moment $P_{b b}$ of $\mathrm{C}_{3} \mathrm{H}_{6} \cdot \mathrm{SO}_{2}\left(54.2495 \mathrm{amu} \AA^{2}\right)$ with $P_{b b}$ of $\mathrm{C}_{3} \mathrm{H}_{6} \cdot{ }^{34} \mathrm{SO}_{2}\left(54.2460 \mathrm{amu} \AA^{2}\right)$ indicates that the $\mathrm{S}$ atom lies in this plane. $P_{b b}$ for the complex is also equal to the sum of $P_{a a}$ of free $\mathrm{SO}_{2}$ and $P_{c c}$ of free cyclopropane, placing the

TABLE V. Planar second moments $\left[P_{a a}=0.5\left(I_{c}+I_{b}-I_{a}\right)=\Sigma m_{i} a_{1}^{2}\right.$ and similarly for $\left.P_{b b}, P_{c c}\right]$ of cyclopropane- $\mathrm{SO}_{2}$, cyclopropane and sulfur dioxide.

\begin{tabular}{lrrcc}
\hline \hline & $\mathrm{C}_{3} \mathrm{H}_{6} \cdot \mathrm{SO}_{2}$ & $\mathrm{C}_{3} \mathrm{H}_{6} \cdot{ }^{34} \mathrm{SO}_{2}$ & Cyclopropane & $\mathrm{SO}_{2}$ \\
\hline$P_{s a} / \mathrm{amu} \AA^{2}$ & 374.0012 & 377.8599 & 20.1254 & 48.7679 \\
$P_{b b} / \mathrm{amu} \AA^{2}$ & 54.2495 & 54.2460 & 20.1254 & 8.3574 \\
$P_{c c} / \mathrm{amu} \AA^{2}$ & 27.5716 & 27.8239 & 5.0262 & 0.0 \\
\hline
\end{tabular}




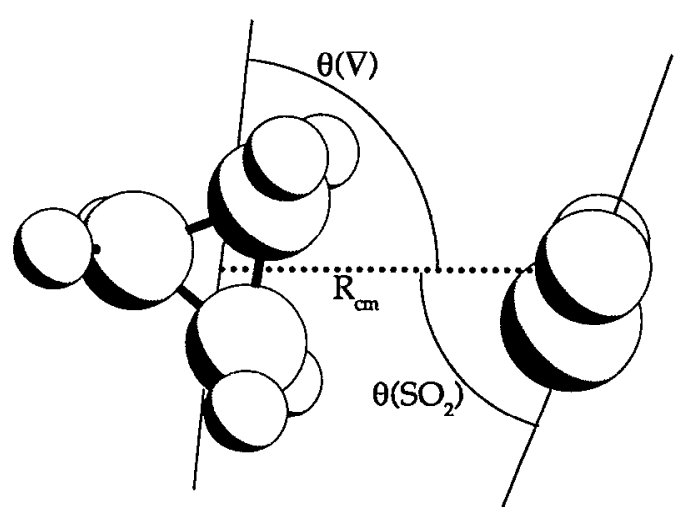

FIG. 1. Definition of structural parameters for cyclopropane $\cdot \mathrm{SO}_{2} \cdot R_{\text {c.m. }}$ is the distance from between the centers of mass, $\theta(\nabla)$ is the angle between $R_{\mathrm{c} . \mathrm{m}}$ and the line parallel to the bonded $\mathrm{C}-\mathrm{C}$ bond running through the center of mass of cyclopropane, and $\theta\left(\mathrm{SO}_{2}\right)$ is the angle between the $C_{2}$ axis of $\mathrm{SO}_{2}$ and $R_{\mathrm{c}, \mathrm{m}}$.

$C_{2}$ axis of $\mathrm{SO}_{2}$ and the $a b$ plane of cyclopropane in the $a c$ plane of the complex. This orientation is shown in Fig. 1 with the $\mathrm{S}$ and $\mathrm{C}$ atoms in the $a c$ symmetry plane and the $\mathrm{O}$ and $\mathrm{H}$ atoms straddling it. Once this is established, the geometry of the complex can be described by the three coordinates in Fig. $1: R_{\text {c.m. }}$, the distance between the centers of mass of the $\mathrm{SO}_{2}$ and the cyclopropane; $\theta\left(\mathrm{SO}_{2}\right)$, the angle between the $C_{2}$ axis of $\mathrm{SO}_{2}$ and $R_{\text {c.m. }} ; \theta(\nabla)$, the angle subtended by $R_{\text {c.m. }}$. and a line through the center of mass of cyclopropane parallel to the $\mathrm{C}-\mathrm{C}$ bond to which the $\mathrm{SO}_{2}$ is bonded. These angles define the tilt of the cyclopropane or the $\mathrm{SO}_{2}$ from perpendicular to $R_{\text {c.m. }}$, i.e., $\theta(\nabla)=\theta\left(\mathrm{SO}_{2}\right)=90^{\circ}$ corresponds to no tilt.

With the symmetry of the molecule deduced, a brief comment about the spectra of the deuterated isotopes is appropriate before proceeding with a discussion of the structure. The relative orientation of the cyclopropane and the $\mathrm{SO}_{2}$ permits three different isomers to exist for both $\mathrm{C}_{3} \mathrm{H}_{5} \mathrm{D} \cdot \mathrm{SO}_{2}$ and $\mathrm{C}_{3} \mathrm{H}_{4} \mathrm{D}_{2} \cdot \mathrm{SO}_{2}$. In each case the isotopic substitution could be on either of the $\mathrm{CH}_{2}$ groups in the $\mathrm{C}-\mathrm{C}$ bond which is closest to the $\mathrm{SO}_{2}$ (labeled basal species), or on the $\mathrm{CH}_{2}$ group opposite that bond (apical). In the case of $\mathrm{C}_{3} \mathrm{H}_{5} \mathrm{D} \cdot \mathrm{SO}_{2}$, due to difficulties with the synthesis, only one spectrum was observed before the sample was depleted. The rotational constants indicated that it was one of the basal isomers. For the $\mathrm{C}_{3} \mathrm{H}_{4} \mathrm{D}_{2} \cdot \mathrm{SO}_{2}$, two spectra were observed: one was consistent with the $\mathrm{D}_{2}$ in the apical position and the other with $\mathrm{D}_{2}$ in one of the basal positions. Although efforts were made to find the spectrum of the third species, it was not observed.

Little information could be gleaned from the moments of inertia of the normal isotopic species alone. Because the $b$ coordinates of all the atoms are fixed by symmetry and the geometries of the monomers, only the $P_{a a}$ and $P_{c c}$ moments of inertia are useful for structure determination. The result is that $R_{\text {c.m. }}$ can be determined from $I_{b}$ as approximately 3.73 $\AA$ but a series of correlated values for $\theta\left(\mathrm{SO}_{2}\right)$ and $\theta(\nabla)$ are obtained from a single isotopic species.

In determining the structure by least-squares fitting of the moments of inertia of all the isotopic species, a choice must be made about assignment of the $\mathrm{C}_{3} \mathrm{H}_{4} \mathrm{D}_{2} \cdot \mathrm{SO}_{2}$ isotopic spectra. The assignment of one spectrum to the species substituted at the apical position and one substituted at the basal position was unambiguous based on the isotope shifts. However, the latter could be assigned to the $\mathrm{CD}_{2}$ group either at the $\mathrm{S}$ or $\mathrm{O}$ atom side of the $\mathrm{SO}_{2}$ (see Fig. 1). The same ambiguity occurs in the location of the basal deuterium in the $\mathrm{C}_{3} \mathrm{H}_{5} \mathrm{D} \cdot \mathrm{SO}_{2}$. Both assignments were tried and they resulted in the two fits shown in Table VI. It was evident that the $\mathrm{CH}_{2}-\mathrm{CD}_{2}$ or $\mathrm{CH}_{2}-\mathrm{CHD}$ bond is tilted slightly to the $\mathrm{SO}_{2}$ and that the $\mathrm{D}_{2}$ (or $\mathrm{D}_{1}$ ) substitution occurs at the carbon closer to the $\mathrm{SO}_{2}$. The quality of the fits is similar because the coordinates of the deuterium are nearly identical in both structures.

Kraitchman's equations were used to calculate the positions of the substituted atoms. ${ }^{21}$ They are compared with the values from the least-squared fit in Table VI. The coordinates determined for the $\mathrm{C}_{3} \mathrm{H}_{5} \mathrm{D} \cdot \mathrm{SO}_{2}$ species and the basal$\mathrm{C}_{3} \mathrm{H}_{4} \mathrm{D}_{2} \cdot \mathrm{SO}_{2}$ species are the same and indicate the basal substitution with the $\mathrm{CD}_{2}$ group nearer the $\mathrm{SO}_{2}$. The coordinates determined for the apical- $\mathrm{C}_{3} \mathrm{H}_{4} \mathrm{D}_{2} \cdot \mathrm{SO}_{2}$ species place the hydrogen atom near to the $a$ axis and much further from the $\mathrm{SO}_{2}$. The substitution coordinates do not, however, distinguish between the two structures. The $\mathrm{S}$ and $\mathrm{O}$ coordinates from Kraitchman's equations are included in Table VI for completeness.

A similar ambiguity about the sign of an angle was encountered in the $\mathrm{C}_{2} \mathrm{H}_{4} \cdot \mathrm{SO}_{2}$ complex, where the tilt angle of the ethylene was difficult to determine. ${ }^{13}$ This was resolved by examining the change in the dipole moment projections

TABLE VI. Structural parameters and atomic coordinates obtained from least-squares fitting of moments of inertia and Kraitchman equations.

\begin{tabular}{lllll}
\hline \hline & & Fit $1^{*}$ & Fit $2^{\mathrm{a}}$ & Kraitchman \\
\hline$R_{\mathrm{cm}} / \AA^{\mathrm{b}}$ & & $3.729(1)$ & $3.729(1)$ & \\
$\theta\left(\mathrm{SO}_{2}\right) / \mathrm{deg}$ & & $73.2(1.7)$ & $73.3(1.7)$ & \\
$\theta(\nabla) / \mathrm{deg}$ & $83.3(2.4)$ & $96.8(2.4)$ & \\
$\Delta I_{\mathrm{rms}} / \mathrm{amu} \AA^{2}$ & 0.52 & 0.52 & \\
$\mathrm{~S}$ & $a$ & $1.37 \AA$ & $1.38 \AA$ & $1.40 \AA$ \\
& $b$ & 0.0 & 0.0 & 0.0 \\
$\mathrm{O}$ & $c$ & 0.36 & 0.36 & 0.36 \\
& $a$ & 1.58 & 1.58 & 1.52 \\
& $b$ & 1.24 & 1.24 & 1.24 \\
$\mathrm{H}^{\mathrm{c}}$ (basal) $)$ & $c$ & 0.38 & 0.38 & 0.32 \\
& $a$ & 1.38 & 1.39 & $1.26^{\mathrm{c}}$ \\
& $b$ & 0.91 & 0.91 & 0.89 \\
$\mathrm{H}^{\mathrm{d}}$ (apical) $)$ & $a$ & 1.17 & 1.15 & 1.21 \\
& $b$ & 3.69 & 3.69 & $3.67^{\mathrm{e}}$ \\
& $b$ & 0.91 & 0.91 & 0.89 \\
& $c$ & 0.19 & 0.15 & 0.26
\end{tabular}

Least-squares fit of 24 moments of inertia ( $A_{2}$ symmetry state) from the eight isotopic species in Table IV. Fit 1 is preferred by the authors (see text).

${ }^{b}$ See Fig. 1 for definition of coordinates.

${ }^{\circ} \mathrm{H}$ (basal) is the hydrogen at the carbon position in the $\mathrm{CH}_{2}-\mathrm{CH}_{2}$ bond which is closest to the $\mathrm{SO}_{2}$ (see Fig. 2).

${ }^{d} \mathrm{H}$ (apical) is the hydrogen at the carbon most distant from the $\mathrm{SO}_{2}$ (see Fig. 2).

'Calculated from the $1,1-\mathrm{C}_{3} \mathrm{H}_{4} \mathrm{D}_{2} \cdot \mathrm{SO}_{2}$ species. 

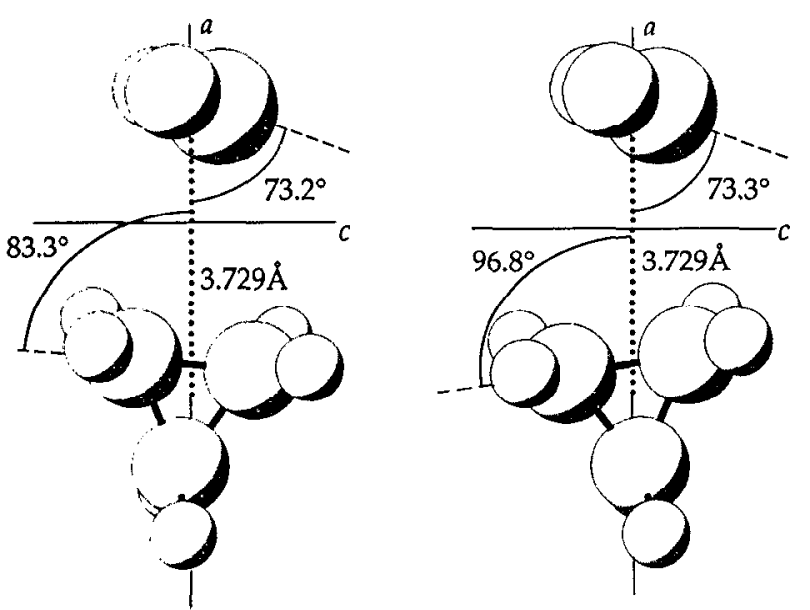

FIG. 2. Two structures of cyclopropane $\cdot \mathrm{SO}_{2}$ determined from leastsquares fitting of the moments of inertia. The structure on the left with $\theta(\nabla)=83.3^{\circ}$ is preferred.

upon isotopic substitution. A similar analysis was employed here. When a molecule is isotopically substituted, its principal inertial axes translate and rotate. The result of the rotation is a small change in the projections of the dipole moment on the principal axes. It is assumed that the change in the total dipole moment upon isotopic substitution is negligible.
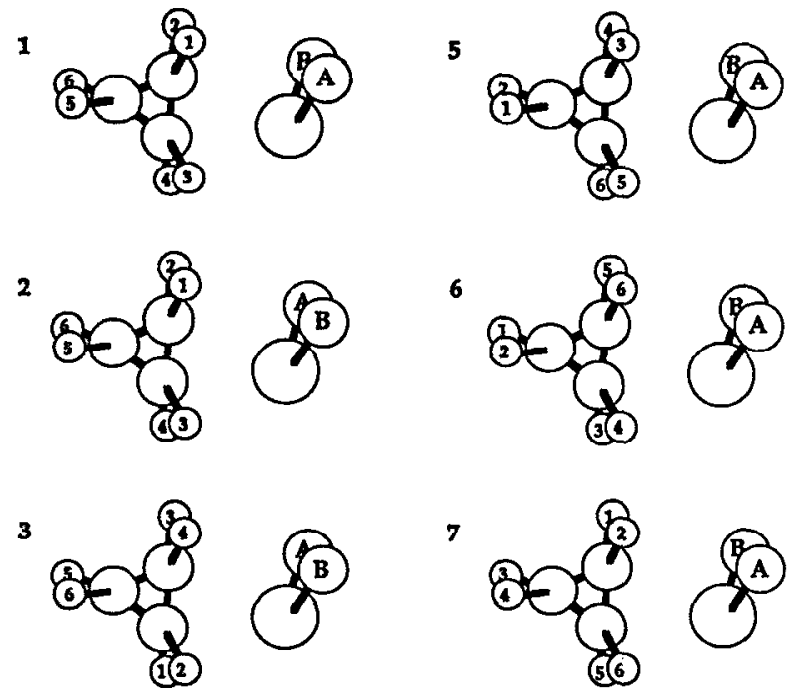

7
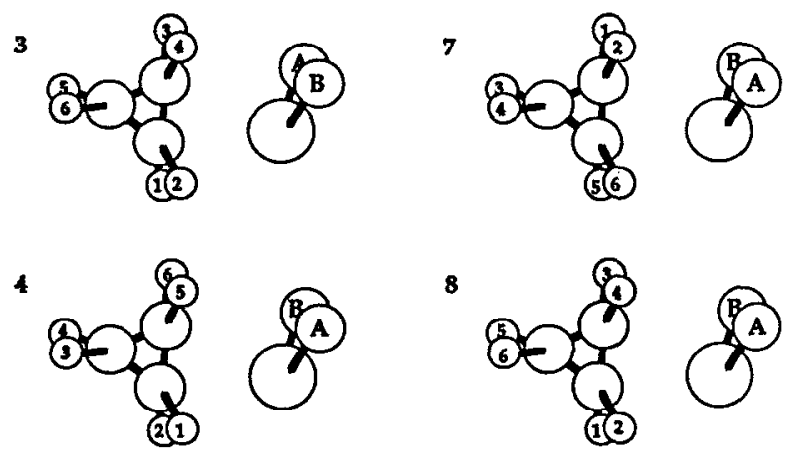

8
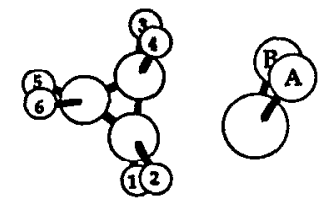

FIG. 3. Feasible permutation of nuclei which were considered to account for tunneling splittings in the spectrum of $\mathrm{C}_{3} \mathrm{H}_{6} \cdot \mathrm{SO}_{2}$. Permutations and likely pathways are $1 \rightarrow 2(a b)$, rotation of $\mathrm{SO}_{2}$ about its local $C_{2}$ axis; $1 \rightarrow 3$ $(a b)(14)(23)(56)$, inversion of $\mathrm{SO}_{2} ; 1 \rightarrow 4$ (135)(246) and $1 \rightarrow 5$ (153)(264), rotation of cyclopropane about its $C_{3}$ axis; $1 \rightarrow 6$ $(34)(16)(25), 1 \rightarrow 7(12)(36)(45)$, and $1 \rightarrow 8(14)(23)(56)$, rotations of cyclc ropane about each of its $C_{2}$ axes.
TABLE VII. Predicted and observed dipole moments for basal-1,1$\mathrm{C}_{3} \mathrm{H}_{4} \mathrm{D}_{2} \cdot \mathrm{SO}_{2}$ for the two structures with $\theta(\nabla)=83.3^{\circ}$ and $\theta(\nabla)=96.8^{\circ}$.

\begin{tabular}{cccc}
\hline & $\theta(\nabla)=83.3^{\circ}$ & $\theta(\nabla)=96.8^{\circ}$ & Obs. \\
\hline$\mu_{a} / \mathrm{D}$ & 0.802 & 0.829 & $0.803(3)$ \\
$\mu_{c} / \mathrm{D}$ & 1.478 & 1.463 & $1.482(3)$ \\
\hline
\end{tabular}

This should be a reasonable assumption for $\mathrm{C}_{3} \mathrm{H}_{4} \mathrm{D}_{2} \cdot \mathrm{SO}_{2}$. The dipole moment of $1,1-\mathrm{C}_{3} \mathrm{H}_{4} \mathrm{D}_{2}$ has been measured as $0.011(5) \mathrm{D}^{22}$ and the total dipole moments of the $\mathrm{C}_{3} \mathrm{H}_{4} \mathrm{D}_{2} \cdot \mathrm{SO}_{2}$ and $\mathrm{C}_{3} \mathrm{H}_{6} \cdot \mathrm{SO}_{2}$ differ by only $0.006(4) \mathrm{D}$. It is also assumed that the effect of vibrational averaging on the momomer and induced dipole moments is not dependent on the direction of $\theta(\nabla)$. A quantitative estimate of these effects is difficult. However, the success of the method in the $\mathrm{C}_{2} \mathrm{H}_{4} \cdot \mathrm{SO}_{2}$ problem, where several cross checks of the structure were available, suggests that averaging effects on the dipole moments can be neglected. The two options for the assignment of the basal $\mathrm{CD}_{2}$ spectrum rotate the axes in opposite directions. For both rotations the $a$ - and $c$-dipole components were predicted and they are shown in Table VII. The direction of the dipole moment of the complex is selected such that it is dominated by the permanent dipole moment of $\mathrm{SO}_{2}{ }^{23}$ The observed dipole components for basal $-\mathrm{C}_{3} \mathrm{H}_{4} \mathrm{D}_{2} \cdot \mathrm{SO}_{2}$ indicate $\theta(\nabla)=83.3^{\circ}$. The uncertainties for $R_{\text {c.m. }}$ and the tilt angles in Table VI are the statistical uncertainties arising from the fitting process. The structural parameters are the so-called $r_{0}$ values. ${ }^{24}$ It is difficult to estimate how closely they approximate the equilibrium values due to the large amplitude vibrational motions in such complexes; it is probably reasonable to expect these values to be within $\pm 0.03 \AA$ for $R_{\text {c.m. }}$ and $\pm 5^{\circ}$ for the tilt angles.

\section{Internal rotation}

The splitting in the $c$-type transitions signifies that a tunneling motion occurs between two or more equivalent configurations in the complex. In an attempt to determine the tunneling path, the feasible permutations of identical nuclei shown in Fig. 3 were considered. Possible tunneling paths for the permutations are the following: $1 \rightarrow 2$, rotation of $\mathrm{SO}_{2}$ about its $C_{2}$ axis; $1 \rightarrow 3$, inversion of $\mathrm{SO}_{2}$ through a $C_{2 v}$ intermediate structure; $1 \rightarrow 4$ and $1 \rightarrow 5$, rotation of cyclopropane about its $C_{3}$ axis; $1 \rightarrow 6$ and $1 \rightarrow 7$, rotation of cyclopropane about either of its $C_{2}$ axes including the bond $\mathrm{CH}_{2}$ groups (the symmetry arguments are the same for both); $1 \rightarrow 8$, rotation of cyclopropane about its $C_{2}$ axis including the apical $\mathrm{CH}_{2}$ group.

The $1 \rightarrow 2$ and $1 \rightarrow 3$ motions can be eliminated as the source of the tunneling doublets based on the spectrum of the normal isotopic species. If the tunneling path were $1 \rightarrow 2$, two identical oxygen atoms $(I=0)$ would be exchanged and half the levels would have zero nuclear spin weight. For the $1 \rightarrow 3$ motion, the direction of the $c$-dipole moment reverses, resulting in $c$-dipole selection rules between the $A_{1}$ and $A_{2}$ symmetry states. Since the two sets of $c$-type transitions may be fit separately, the observed selection rules are inconsistent with this tunneling path. 
The remaining tunneling paths involve the cyclopropane subunit, therefore, the deuterated isotopomers were instrumental in exploring them. From structural considerations alone, three isomers would be expected for the 1,1- $\mathrm{C}_{3} \mathrm{H}_{4} \mathrm{D}_{2} \cdot \mathrm{SO}_{2}$ : one with the $\mathrm{CD}_{2}$ group in the basal position at the $\mathrm{S}$ of the $\mathrm{SO}_{2}$, a second in the basal position at the $\mathrm{O}$ of the $\mathrm{SO}_{2}$, and the third in the apical position. Referring to framework 1 in Fig. 3, these correspond to substitution in positions 3 and 4, positions 1 and 2, and positions 5 and 6 , respectively. The tunneling paths under consideration, however, would result in different splitting patterns for the different isomers. For the $1 \rightarrow 4$ and $1 \rightarrow 5$ motions, rotation of cyclopropane about its $C_{3}$ axis, none of the $\mathrm{C}_{3} \mathrm{H}_{4} \mathrm{D}_{2} \cdot \mathrm{SO}_{2}$ spectra should be split. This path would exchange the $\mathrm{CD}_{2}$ group among three structurally inequivalent frameworks which have different moments of inertia. With the exception of $\mathrm{H}^{35} \mathrm{Cl} \cdot \mathrm{H}^{37} \mathrm{Cl}$, tunneling doublets are generally not observed under those conditions. ${ }^{25}$ The $1 \rightarrow 6$ and $1 \rightarrow 7$ motions would produce a split spectrum for the basal $\mathrm{CD}_{2}$ group on the $C_{2}$ axis about which the cyclopropane rotates as this would exchange identical nuclei. However, unsplit spectra would be expected for the the $\mathrm{CD}_{2}$ group at the other basal and the apical positions. For the $1 \rightarrow 8$ path, the $\mathrm{CD}_{2}$ group in the apical position results in the exchange of identical atoms and tunneling doublets, while both the basal $\mathrm{CD}_{2}$ groups are distinct and would be unsplit. The observation of splittings in the spectrum of the $\mathrm{CD}_{2}$ group in the apical position and an unsplit spectrum for the $\mathrm{CD}_{2}$ group in the basal position then indicates that the $1 \rightarrow 8$ motion is the correct tunneling path. This would produce nuclear spin statistical weights of approximately $1: 1.3$ in the normal isotopic form and, although the relative intensities of the two states could not be measured, they are estimated to be between 1:1 and 1:2.

It should be noted that the $1 \rightarrow 8$ path is described as rotation of cyclopropane about its $C_{2}$ axis. This facilitates the discussion of the symmetry but does not necessarily imply that the $\mathrm{SO}_{2}$ is a fixed framework on which the cyclopropane rotates. Although this division is common and a good description when the masses of the two parts are very different, such a separation is not obvious for $\mathrm{C}_{3} \mathrm{H}_{6} \cdot \mathrm{SO}_{2}$. Perhaps a geared rotation of the two subunits against one another would be a more appropriate description. There is some suggestion of this since the magnitude of the tunneling splitting is affected not only by isotopic substitution on the cyclopropane, but also on the sulfur dioxide. It is not trivial to estimate the barrier from the observed splittings and this was not attempted.

Finally, it is interesting that out of three possible structural isomers for $1,1-\mathrm{C}_{3} \mathrm{H}_{4} \mathrm{D}_{2} \cdot \mathrm{SO}_{2}$, only two were observed. While it is not uncommon under supersonically cooled beam conditions for only the isotopomer with the lowest zeropoint energy to be populated, ${ }^{26}$ the observation of two out of three isomers is puzzling. The tunneling path seems to shed some light on this. Based on statistical arguments, it is equally likely that the $\mathrm{SO}_{2}$ will bond to any of the three $\mathrm{C}-\mathrm{C}$ bonds in the $1,1-C_{3} H_{4} D_{2}$ species when the complexes are formed in the nozzle. If the two bond positions have different zeropoint energies, a path exists for cooling to the lower energy basal position through the tunneling coordinate, i.e., the internal rotation pathway is a means for equilibrating between the two $\mathrm{CD}_{2}$ bond isomers. However, there is no ready pathway for cooling between the basal and apical positions if the barrier to exchange for this motion is very high, and both of these forms remain populated at the level determined by the beam kinetics.

\section{DISCUSSION}

The structure of $\mathrm{C}_{3} \mathrm{H}_{6} \cdot \mathrm{SO}_{2}$ is similar to the structures of $\mathrm{C}_{2} \mathrm{H}_{4} \cdot \mathrm{SO}_{2}$ and $\mathrm{C}_{2} \mathrm{H}_{2} \cdot \mathrm{SO}_{2}$ in that the $\mathrm{S}$ atom is closest to the pseudo- $\pi$ system of the cyclopropane. The symmetry, however, is different with the dihedral angle $(\alpha)$ between the $C_{2}$ axis of the $\mathrm{SO}_{2}$ and the $\mathrm{C}-\mathrm{C}$ bond equal to $0^{\circ}$ for $\mathrm{C}_{3} \mathrm{H}_{6} \cdot \mathrm{SO}_{2}$ compared to $90^{\circ}$ for $\mathrm{C}_{2} \mathrm{H}_{4} \cdot \mathrm{SO}_{2}$ and $\mathrm{C}_{2} \mathrm{H}_{2} \cdot \mathrm{SO}_{2}$. To explore whether this could be attributed to electrostatic considerations alone, the distributed multipole (DMA) model of Buckingham and Fowler was employed. ${ }^{27}$ Distributed multipoles for $\mathrm{SO}_{2}$ were taken directly from Buckingham and Fowler, while those for cyclopropane were calculated using the CADPAC program with a DZP (double zeta plus polarization) basis set. ${ }^{28}$ The coordinates and multipoles are listed in Table VIII. The DMA gives a minimum of energy at the $\alpha=0^{\circ}$ geometry with $\theta\left(\mathrm{SO}_{2}\right)=90^{\circ}$ and $\theta(\nabla)$ $=75^{\circ}$, which are considerably different from the experimental angles. The well seems to be very shallow, however, and the experimental geometry $\theta\left(\mathrm{SO}_{2}\right)=74^{\circ}, \theta(\nabla)=84^{\circ}$ is only $13 \mathrm{~cm}^{-1}$ higher in energy. The lowest-energy structure for $\alpha=90^{\circ}$ is $75 \mathrm{~cm}^{-1}$ higher in energy.

TABLE VIII. Cyclopropane distributed multipole moments in atomic units.

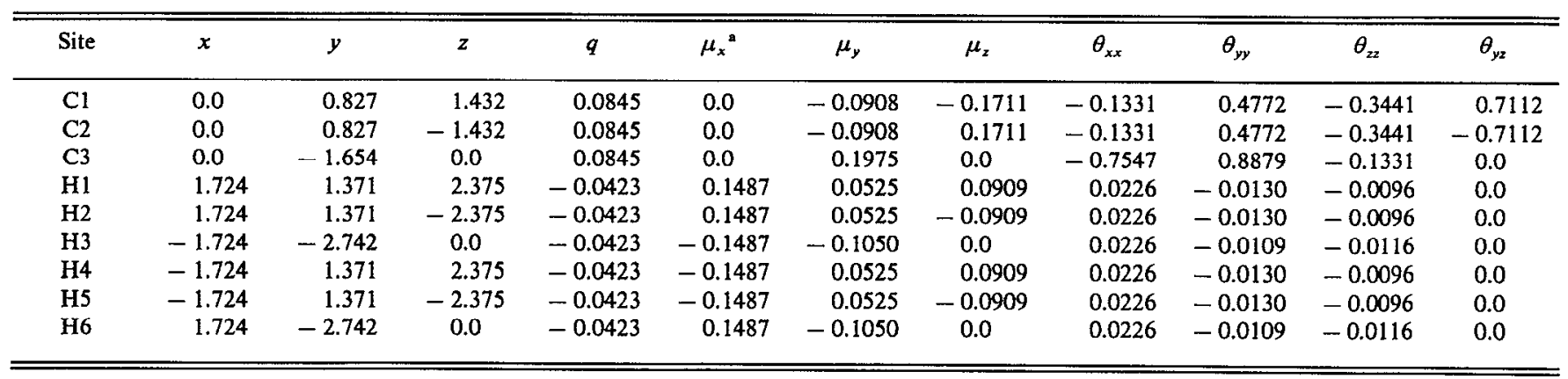

${ }^{2}$ Dipole moment directions are from regions of negative to positive charge. 
TABLE IX. Comparison of the complexes of cyclopropane, acetylene, and ethylene.

\begin{tabular}{|c|c|c|c|c|}
\hline & & Cyclopropane & Acetylene & Ethylene \\
\hline \multirow[t]{7}{*}{$\overline{\mathrm{SO}_{2}}$} & $R / \AA^{\sharp}$ & 3.203 & 3.359 & 3.446 \\
\hline & $k /$ mdyne $\AA^{-\mathrm{ab}}$ & 0.059 & 0.047 & 0.057 \\
\hline & $\mathrm{\epsilon} / \mathrm{cm}^{-1 \mathrm{c}}$ & 652 & 390 & 490 \\
\hline & $\mu_{0}$ (ind) $/ \mathrm{D}^{\mathrm{d}}$ & 0.349 & 0.326 & 0.289 \\
\hline & $\mu_{c}($ ind $) / D^{d}$ & 0.095 & 0.063 & 0.072 \\
\hline & $\mu_{I}$ (ind)/D $/ \mathrm{D}^{\mathrm{d}}$ & 0.361 & 0.332 & 0.298 \\
\hline & Reference & & 14 & 13 \\
\hline \multirow[t]{4}{*}{$\mathrm{HCl}$} & $R / \AA$ & 3.567 & 3.699 & 3.724 \\
\hline & $k /$ mdyne $\AA^{-1}$ & 0.087 & 0.067 & 0.061 \\
\hline & $\epsilon / \mathrm{cm}^{-1}$ & 959 & 614 & 575 \\
\hline & Reference & 8 & 5 & 2 \\
\hline \multirow[t]{4}{*}{$\mathrm{HCN}$} & $R / \AA$ & 3.475 & 3.656 & 3.711 \\
\hline & $k /$ mdyne $\AA^{-1}$ & 0.062 & 0.053 & 0.046 \\
\hline & $\epsilon / \mathrm{cm}^{-1}$ & 862 & 642 & 575 \\
\hline & Reference & 9 & 6 & 3 \\
\hline \multirow[t]{3}{*}{$\mathrm{HF}$} & $R / \AA$ & 3.021 & 3.121 & 3.143 \\
\hline & $\mu_{\mathrm{nnd}} / \mathrm{D}$ & 0.78 & 0.65 & 0.67 \\
\hline & Reference & 7 & 4 & 1 \\
\hline
\end{tabular}

- $R$ is the distance from hydrocarbon $\mathrm{C}-\mathrm{C}$ bond to nearest heavy atom.

${ }^{b} k$ is the pseudodiatomic stretching force constant.

$\therefore \epsilon$ is the pseudodiatomic well depth.

${ }^{d}$ Induced dipole moment/D (see text).

The appropriate hydrocarbon $\mathrm{X}$ distances, stretching force constants, well depths, and induced dipole moments for the cyclopropane, ethylene, and acetylene complexes with $\mathrm{SO}_{2}, \mathrm{HCl}, \mathrm{HCN}$, and $\mathrm{HF}$ are shown in Table IX. The pseudodiatomic stretching force constant for $\mathrm{C}_{3} \mathrm{H}_{6} \cdot \mathrm{SO}_{2}$ was calculated using Millen's model ${ }^{29}$ as 0.059 mdyne/Å and from this the binding energy was estimated as $650 \mathrm{~cm}^{-1}$. The induced dipole moments for the HF complexes were taken from Nelson, Fraser, and Klemperer ${ }^{11}$ as $\mu_{\text {ind }}=\mu-\langle\cos \theta\rangle \mu_{\mathrm{HF}}$, where $\langle\cos \theta\rangle$ is approximated by $\left\langle\cos ^{2} \theta\right\rangle^{1 / 2}$ which is determined from hyperfine interaction constants. For the $\mathrm{SO}_{2}$ complexes an estimate of the averaging effects from bending motions on the dipole moments is not so straightforward as there are no hyperfine interactions giving information on the $\mathrm{SO}_{2}$ bending vibration. These effects were neglected and the induced moments were taken as the difference between the observed dipole components and the projections of the $\mathrm{SO}_{2}$ permanent dipole moment on the principal axes of the complex.

The $\mathrm{SO}_{2}$ complexes exhibit the same decrease in sulfur to the $\mathrm{C}-\mathrm{C}$ bond center distance previously noted for the hydrogen-bonded complexes. There is an increase in induced dipole moment in the series ethylene, acetylene, and cyclopropane, while in the $\mathrm{HF}$ complexes, the induced dipole moment is about the same for $\mathrm{C}_{2} \mathrm{H}_{2} \cdot \mathrm{HF}$ and $\mathrm{C}_{2} \mathrm{H}_{4} \cdot \mathrm{HF}$ and larger for $\mathrm{C}_{3} \mathrm{H}_{6} \cdot \mathrm{HF}$. The force constants and binding energies are also greater for $\mathrm{C}_{3} \mathrm{H}_{6} \cdot \mathrm{SO}_{2}$ than $\mathrm{C}_{2} \mathrm{H}_{2} \cdot \mathrm{SO}_{2}$. The values for $\mathrm{C}_{2} \mathrm{H}_{4} \cdot \mathrm{SO}_{2}$ are anomalously high, most probably because of perturbations in the spectrum due to a tunneling motion which contaminates the distortion constants. The difficulty with the $\mathrm{C}_{2} \mathrm{H}_{4} \cdot \mathrm{SO}_{2}$ distortion constants aside, it is reasonable to conclude from the other data that $\mathrm{C}_{3} \mathrm{H}_{\mathrm{o}} \cdot \mathrm{SO}_{2}$ is the most strongly bound of the three, consistent with the finding of Legon and Millen that $\mathrm{C}_{3} \mathrm{H}_{6}$ is the best nucleophile. ${ }^{12 \mathrm{~b}}$
Legon and Millen's model for determining nucleophilicities and electrophilicities has been successful in interpreting hydrogen-bonded complexes, but it has not yet been applied to other weak complexes. Because many $\mathrm{SO}_{2}$ complexes have been characterized in recent years, the $\mathrm{C}_{x} \mathrm{H}_{y} \cdot \mathrm{SO}_{2}$ complexes seemed an ideal situation to test it. The formula for relating nucleophilicities and electrophilicities to the pseudodiatomic stretching force constant is ${ }^{12 z}$

$$
k_{o}=c N E
$$

where $k_{\sigma}$ is the force constant, $c$ is a proportionality constant (equal to about 0.25 ), $N$ is the nucleophilicity of the nucleophile, and $E$ is the electrophilicity of the electrophile. Using $N=6.4$ for cyclopropane as determined by Legon and Millen, $E$ for $\mathrm{SO}_{2}$ was calculated as 3.7. This was then used to predict $k_{\sigma}$ for a number of $\mathrm{SO}_{2}$ complexes with molecules for which the nucleophilicities have been calculated. These are shown in Table $\mathrm{X}$ along with the experimentally deter-

TABLE X. Pseudodiatomic stretching force constants for $\mathrm{SO}_{2}$ containing complexes.

\begin{tabular}{lccc}
\hline & $\begin{array}{c}k_{\sigma} / 10^{-2} \text { mdyne }^{-1} \\
\text { Predicted }^{\mathrm{a}}\end{array}$ & Observed & \\
& Reference \\
\hline $\mathrm{C}_{3} \mathrm{H}_{6} \cdot \mathrm{SO}_{2}{ }^{\mathrm{c}}$ & 5.9 & 5.9 & \\
$\mathrm{C}_{2} \mathrm{H}_{2} \cdot \mathrm{SO}_{2}$ & 4.7 & 4.7 & 14 \\
$\mathrm{H}_{2} \mathrm{O} \cdot \mathrm{SO}_{2}$ & 9.3 & 8.4 & 32 \\
$\mathrm{H}_{2} \mathrm{~S} \cdot \mathrm{SO}_{2}$ & 4.4 & 5.3 & 33 \\
$\mathrm{HCN} \cdot \mathrm{SO}_{2}$ & 6.7 & 2.7 & 34 \\
$\left(\mathrm{CH}_{3}\right)_{2} \mathrm{O} \cdot \mathrm{SO}_{2}$ & 10.4 & 6.8 & 35 \\
\hline
\end{tabular}

apredicted using nucleophilicity from Ref. 12(b) and electrophilicity of $\mathrm{SO}_{2}=3.7$ (see text).

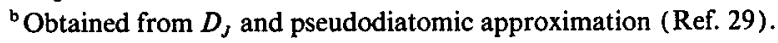

${ }^{\circ} \mathrm{C}_{3} \mathrm{H}_{6} \cdot \mathrm{SO}_{2}$ was used to determine the electrophilicity of $\mathrm{SO}_{2}$; therefore, the match is required to be exact. 
mined $k_{\sigma}$. There is excellent agreement for $\mathrm{C}_{2} \mathrm{H}_{2} \cdot \mathrm{SO}_{2}$ and quite good agreement for $\mathrm{SO}_{2} \cdot \mathrm{H}_{2} \mathrm{O}$ (Ref. 30) and $\mathrm{H}_{2} \mathrm{~S} \cdot \mathrm{SO}_{2}$ (Ref. 31). The agreement for $\mathrm{HCN} \cdot \mathrm{SO}_{2}$ (Ref. 32) and $\left(\mathrm{CH}_{3}\right)_{2} \mathrm{O} \cdot \mathrm{SO}_{2}$ (Ref. 33) is rather poor. These complexes, however, are unusual in that the two subunits are somewhat closer than the sum of their van der Waals radii. In the case of $\left(\mathrm{CH}_{3}\right)_{2} \mathrm{O} \cdot \mathrm{SO}_{2}$ the interaction may involve some chargetransfer interaction. This raises questions about the validity of the psuedodiatomic approximation, but also suggests that the nucleophilicity model is perhaps only applicable to complexes which are bound by primarily electrostatic forces. A larger data set is needed to test whether these complexes represent an anomaly or whether the model does not readily transfer to non-hydrogen-bonded weak complexes.

\section{ACKNOWLEDGMENTS}

This work was supported by a grant from the National Science Foundation. We are grateful for time granted at the San Diego Supercomputing Center. A.M.A. acknowledges the support of a Regents-Baer Fellowship at the University of Michigan.

${ }^{1}$ J. A. Shea and W. H. Flygare, J. Chem. Phys. 76, 4857 (1982).

${ }^{2}$ S. G. Kukolich, P. D. Aldrich, W. G. Read, and E. J. Campbell, Chem. Phys. Lett. 90, 329 (1982).

${ }^{3}$ S. G. Kukolich, W. G. Read, and P. D. Aldrich, J. Chem. Phys. 78, 3552 (1983).

${ }^{4}$ W. G. Read and W. H. Flygare, J. Chem. Phys. 76, 2238 (1982).

${ }^{5}$ A. C. Legon, P. D. Aldrich, and W. H. Flygare, J. Chem. Phys. 75, 625 (1981).

${ }^{6}$ P. D. Aldrich, S. G. Kukolich, and E. J. Campbell, J. Chem. Phys. 78, 3521 (1983).

${ }^{7}$ L. W. Buxton, P. D. Aldrich, J. A. Shea, A. C. Legon, and W. H. Flygare, J. Chem. Phys. 75, 2681 (1981).

${ }^{8}$ A. C. Legon, P. D. Aldrich, and W. H. Flygare, J. Amer. Chem. Soc. 104 1486 (1982); P. D. Aldrich, S. G. Kukolich, E. J. Campbell, and W. G. Read, ibid. 105, 5569 (1983).

'S. G. Kukolich, J. Chem. Phys. 78, 4832 (1983).
${ }^{10}$ C. A. Coulson and W. E. Moffit, J. Chem. Phys. 15, 151 (1947); C. A. Coulson and W. E. Moffit, Philos. Mag. 40, 1 (1949).

${ }^{11}$ D. D. Nelson, Jr, G. T. Fraser, and W. Klemperer, J. Chem. Phys. 82, 4483 (1985).

${ }^{12}$ (a) A. C. Legon and D. J. Millen, J. Amer. Chem. Soc. 109, 356 (1987); (b) A. C. Legon and D. J. Millen, J. Chem. Soc. Chem. Comm. 986 (1987).

${ }^{13}$ A. M. Andrews, A. Taleb-Bendiab, M. S. LaBarge, K. W. Hillig II, and R. L. Kuczkowski, J. Chem. Phys. 93, 7030 (1990).

${ }^{14}$ A. M. Andrews, K. W. Hillig, R. L. Kuczkowski, A. C. Legon, and N. W. Howard, J. Chem. Phys. 94, 6946 (1991).

${ }^{15}$ T. J. Balle and W. H. Flygare, Rev. Sci. Instrum. 52, 33 (1981).

${ }^{16}$ K. W. Hillig II, J. Matos, A. Scioli, and R. L. Kuczkowski, Chem. Phys. Lett. 133, 359 (1987).

${ }^{17}$ J. K. G. Watson, J. Chem. Phys. 46, 1935 (1967).

${ }^{18} \mathrm{~K}$. Tanaka, H. Ito, K. Harada, and T. Tanaka, J. Phys. Chem. 80, 5893 (1984).

${ }^{19}$ Y. Endo, M. C. Chang, and E. Hirota, J. Mol. Spec. 126, 63 (1987).

${ }^{20}$ M. D. Harmony, V. W. Laurie, R. L. Kuczkowski, R. H. Schwendeman, D. A. Ramsey, F. J. Lovas, W. J. Lafferty, and A. G. Maki, J. Chem. Phys. Ref. Data 8, 619 (1979).

${ }^{21}$ J. Kraitchman, Am J. Phys. 21, 17 (1953); A. Chutjian, J. Mol. Spectrose. 14, 361 (1964).

${ }^{22}$ O. Böttcher, N. Heineking, and D. H. Sutter, J. Mol. Spec. 139, 236 (1990).

${ }^{23}$ F. J. Lovas, J. Chem. Phys. Ref. Data, 14, 395 (1985).

${ }^{24}$ R. H. Schwendeman, Critical Evaluation of Chemical and Physical Structural Information, edited by D. R. Lide and M. A. Paul (National Academy of Sciences, Washington, D. C., 1974), pp. 74-115.

${ }^{23}$ N. Ohashi and A. S. Pine, J. Chem. Phys. 81, 73 (1984).

${ }^{26}$ T. R. Dyke, B. J. Howard, and W. Klemperer, J. Chem. Phys. 56, 2442 (1972); H. S. Gutowsky, C. Chuang, J. D. Keen, T. D. Klots, and T. Emilsson, J. Chem. Phys. 83, 2070 (1985).

${ }^{27}$ A. D. Buckingham and P. W. Fowler, Can. J. Chem. 63, 2018 (1985).

${ }^{28}$ R. D. Amos and J. E. Rice, Cambridge Analytical Derivatives Package, Issue 4.0, Cambridge, 1987.

${ }^{29}$ D. J. Millen, Can. J. Chem. 63, 1477 (1985).

${ }^{30} \mathrm{~K}$. Matsumura, F. J. Lovas, and R. D. Suenram, J. Chem. Phys. 91, 5887 (1989).

${ }^{31}$ R. E. Bumgarner, D. J. Pauley, and S. G. Kukolich, J. Chem. Phys. 87, 3749 (1987); D. J. Pauley, and S. G. Kukolich, ibid. 93, 1487 (1990).

${ }^{32}$ E. J. Goodwin and A. C. Legon, J. Chem. Phys. 85, 6828 (1986).

${ }^{33}$ J. J. Oh, K. W. Hillig II, and R. L. Kuczkowski, Inorg. Chem. (to be published). 